\title{
Desalination and seawater quality at Green Point, \\ Cape Town: A study on the effects of marine sewage outfalls
}

AUTHORS:

Leslie Petrik

Lesley Green ${ }^{2}$

Adeola P. Abegunde ${ }^{1}$

Melissa Zackon ${ }^{2}$

Cecilia Y. Sanusi ${ }^{1}$

Jo Barnes ${ }^{3}$

\section{AFFILIATIONS:}

${ }^{1}$ Environmental and Nano Science Group, Department of Chemistry, University of the Western Cape, Cape Town, South Africa

'Environmental Humanities South and Department of Anthropology, School of African and Gender Studies, Anthropology and Linguistics, University of Cape Town, Cape Town, South Africa

${ }^{3}$ Senior Lecturer Emeritus, Division of Community Health, Stellenbosch University, Stellenbosch, South Africa

\section{CORRESPONDENCE TO: Lesley Green}

\section{EMAIL:}

lesley.green@uct.ac.za

\section{KEYWORDS:}

microbial pollution; pharmaceuticals; perfluorinated compounds; common household chemicals; marine organisms

\section{HOW TO CITE:}

Petrik L, Green L, Abegunde AP, Zackon M, Sanusi CY, Barnes J. Desalination and seawater quality at Green Point, Cape Town: A study on the effects of marine sewage outfalls. S Afr J Sci. 2017;113(11/12), Art. \#a0244, 10 pages. http://dx.doi. org/10.17159/sajs.2017/a0244

(C) 2017. The Author(s). Published under a Creative Commons Attribution Licence.
This paper presents our collection methods, laboratory protocols and findings in respect of sewage pollution affecting seawater and marine organisms in Table Bay, Cape Town, South Africa, then moves to consider their implications for the governance of urban water as well as sewage treatment and desalination. A series of seawater samples, collected from approximately $500 \mathrm{~m}$ to $1500 \mathrm{~m}$ offshore, in rock pools at low tide near Granger Bay, and at a depth under beach sand of $300-400 \mathrm{~mm}$, were investigated for the presence of bacteriological load indicator organisms including Escherichia coli and Enterococcus bacteria. A second series of samples comprised limpets (Patella vulgata), mussels (Mytilus galloprovincialis), sea urchins (Tripneustes ventricosus), starfish (Fromia monilis), sea snails (Tegula funebralis) and seaweed (Ulva lactuca), collected in rock pools at low tide near Granger Bay, and sediment from wet beach sand and where the organisms were found, close to the sites of a proposed desalination plant and a number of recreational beaches. Intermittently high levels of microbial pollution were noted, and 15 pharmaceutical and common household chemicals were identified and quantified in the background seawater and bioaccumulated in marine organisms. These indicator microbes and chemicals point to the probable presence of pathogens, and literally thousands of chemicals of emerging concern in the seawater. Their bioaccumulation potential is demonstrated.

In respect of proposed desalination, the findings indicate that desalinated seawater must be subjected to treatment protocols capable of removing both bacterial loads and organic chemical compounds. The terms of reference for desalination plants must specify adequate testing and monitoring of chemical compounds as well as microorganisms in the intake and recovered water. Drinking water supplied by the proposed seawater desalination plants should be carefully tested for its toxicity.

In respect of water management, our findings suggest the need for the City of Cape Town to move to an integrated water and sewage management plan that treats urban water, including seawater, as a circulating system that is integral to the health of the City, and which excludes marine outfalls.

\section{Background to the study}

The ongoing drought in the Western Cape has led to the proposal to produce drinking water via seawater desalination plants for the City of Cape Town. The terms of reference provided in the tender documents make the assumption that the tens of millions of litres a day of untreated sewage effluent discharged into the ocean via the marine outfalls located around the Peninsula are dispersed out to sea and that intake seawater to the desalination plants will contain only inorganic salts, and not organic chemical pollutants or microorganisms.

However, kayakers, long-distance swimmers, and citizen groups like the Camps Bay Ratepayers, have claimed that untreated effluent from the marine outfalls washes back to shore in specific conditions. ${ }^{1,2}$ Where positive independent $E$. coli counts have been demonstrated, such as those collected by public health researcher Edda Weimann ${ }^{3}$, the City has argued that the $E$. coli results are a result of stormwater run-off.

Resolving the matter requires evidence of factors that can only have been sourced from human sewage, such as specific bacteriology and pharmacological compounds that can only have entered seawater via faecal contamination from the marine outfalls and not from surface run-off. If those compounds are present, the findings have relevance to the City's desalination plants, beach management and sewage management system.

Persistent organic pollutants include pharmaceutical and personal healthcare products such as over-the-counter and prescription drugs (antibiotics, analgesics, blood lipid regulators, natural and synthetic hormones, $\beta$-blockers, antidiabetics, antihypertensives, etc.) and household products such as soaps, detergents, disinfectants, perfumes, dental care products, skin and hair products, and surfactants, as well as these compounds' degradation products. ${ }^{4-6}$ There is growing evidence that certain emerging contaminants could affect human and environmental health. For example, the veterinary use of diclofenac, which is also a human pharmaceutical used as an anti-inflammatory treatment, was found to be responsible for the massive decline in populations of vulture species in certain areas of $\mathrm{Asia}^{7}$; ethinylestradiol, one of the active ingredients in the contraceptive pill, has been associated with endocrine disruption and feminisation in fish ${ }^{8}$; and there is concern that long-term exposure to antibiotic pharmaceuticals and disinfectant products may be contributing to the selection of resistant bacteria with significant impacts upon human health. ${ }^{9}$ In South Africa, Ncube et al. ${ }^{10}$ suggested a protocol for the selection and prioritisation of contaminants in drinking water. Patterton ${ }^{11}$ surveyed seven cities in South Africa and showed the presence of 32 compounds in drinking water, predominantly pharmaceuticals and pesticides, including carbamazepine (anticonvulsant), phenytoin (antiepileptic) and diclofenac. Osunmakinde et al. ${ }^{12}$ compiled a priority list including the antiretroviral lamivudine, based on data collected from the health sector in South Africa. These compounds could cause far more harm than the sewage itself, such as feminisation or sterility of fish populations, cancer, growth deformities, foetal abnormalities and hormonal disturbances. These compounds may bioaccumulate in marine organisms, and thus move up the food chain to humans who eat seafood, ultimately causing the same effects. Also in South Africa, Swartz et al. ${ }^{13}$ identified carbamazepine, sulfamethoxazole (antibiotic), triclosan (biocide), bisphenol A (plasticiser) and caffeine (stimulant) amongst others as priority pollutants for water quality assessment in water reuse. 
These authors stated ${ }^{13}$ :

The priority list cannot be seen as an exhaustive list as each reclaimed potable water reuse project should interrogate the relevance according to the specific area to consider whether extra chemicals might need to be added to the priority list.

These authors also reported that many of the compounds tested for, escaped through the conventional wastewater treatment plants in trace quantities into the environment. For instance, $\alpha$-ethinylestradiol, which has a recommended reference dose of $0.0015 \mu \mathrm{g} / \mathrm{L}$, was present in some effluents at levels of $2-6 \mu \mathrm{g} / \mathrm{L}$.

This study presents the laboratory findings from seawater, sediments as well as samples of marine organisms collected near the marine sewage outfalls in Green Point, close to the site of the proposed Granger Bay desalination plant.

\section{Water samples: Collection methods and laboratory protocols}

Seawater samples for microbiological and chemical testing were collected at 22 different points (Figure 1) near Granger Bay in the months of June, July and August 2017, together with kayakers on days on which winds and swell conditions allowed for kayak trips. In addition, seven samples were taken of water in beach sands of the intertidal swash zone at depths of approximately $300 \mathrm{~mm}$. All water samples for microbiological testing were collected in bottles provided by the South African Bureau of Standards (SABS) in a sealed packet $24 \mathrm{~h}$ prior to collection, and samples were delivered to the SABS laboratories in Rosebank, Cape Town, within $1 \mathrm{~h}$ of collection and stored on ice en route. Tests were requested for $E$. coli as the indicator organism of choice for checking sewage contamination in fresh water while Enterococcus is more stable in seawater. At the SABS laboratories, which are accredited, samples were tested in terms of the SANS 5221 protocol for E. coli and SANS 7899 for Enterococcus. Figure 1 shows the location of sampling points in the ocean and on the shoreline and flags the hot spots of contamination above the Blue Flag limits of 250 colony-forming units per 100 millilitres (CFU/100 mL).

\section{Microbial findings}

The results of microbial tests for seawater and beach water samples are consistent with kayakers' claims that on occasion the water is a health risk. While the majority of markers were clear, there was significant variability. One sample - taken $1.7 \mathrm{~km}$ from shore - contained an E. coli count of $12650 \mathrm{CFU} / 100 \mathrm{~mL}$. This sample was collected on the edge of what kayakers identified as the sewage plume that had led to several complaints, and although the plume was visibly more dense further on, the kayakers were not willing to risk paddling into it to collect additional water samples. On the same day, a sample taken $1 \mathrm{~km}$ from the shore contained an $E$. coli count of $4700 \mathrm{CFU} / 100 \mathrm{~mL}$.

Water collected in sand evidenced similar variability. One sample contained an Enterococcus count of $1460 \mathrm{CFU} / 100 \mathrm{~mL}$ and that on another day had a count of $7200 \mathrm{CFU} / 100 \mathrm{~mL}$. The majority of microbial results were within specification, as shown on the map.

\section{Discussion}

In 2014, Edda Weimann, an endocrinologist, published a paper challenging the City's use of the Blue Flag ensign to promote its beaches. ${ }^{3}$ Her samples, taken six times at Clifton Beach over a 4-week period in early 2013 , showed that only on one day was the $E$. coli level within the Blue Flag acceptable range of below $250 \mathrm{CFU} / 100 \mathrm{~mL}$ and Enterococcus below $100 \mathrm{CFU} / 100 \mathrm{~mL}$. On two separate days she found the values for $E$. coli had been in the tens of thousands, and on a further two days the values ranged in the hundreds of thousands and closer to one million $\left(10^{5}-10^{6}\right)$. Nonetheless, on every day that she had sampled Clifton's waters, the Blue Flag had been hoisted. Weimann's findings contradict Blue Flag's criteria pertaining to water quality. ${ }^{14}$

Both Weimann's findings and ours suggest that predictive modelling will be more effective in managing potentially hazardous beach sewage levels than the form of water quality monitoring currently used in the City via the Blue Flag protocols, which are used to assert the health of the seawater on the basis of one or two samples taken per month..$^{15,16}$

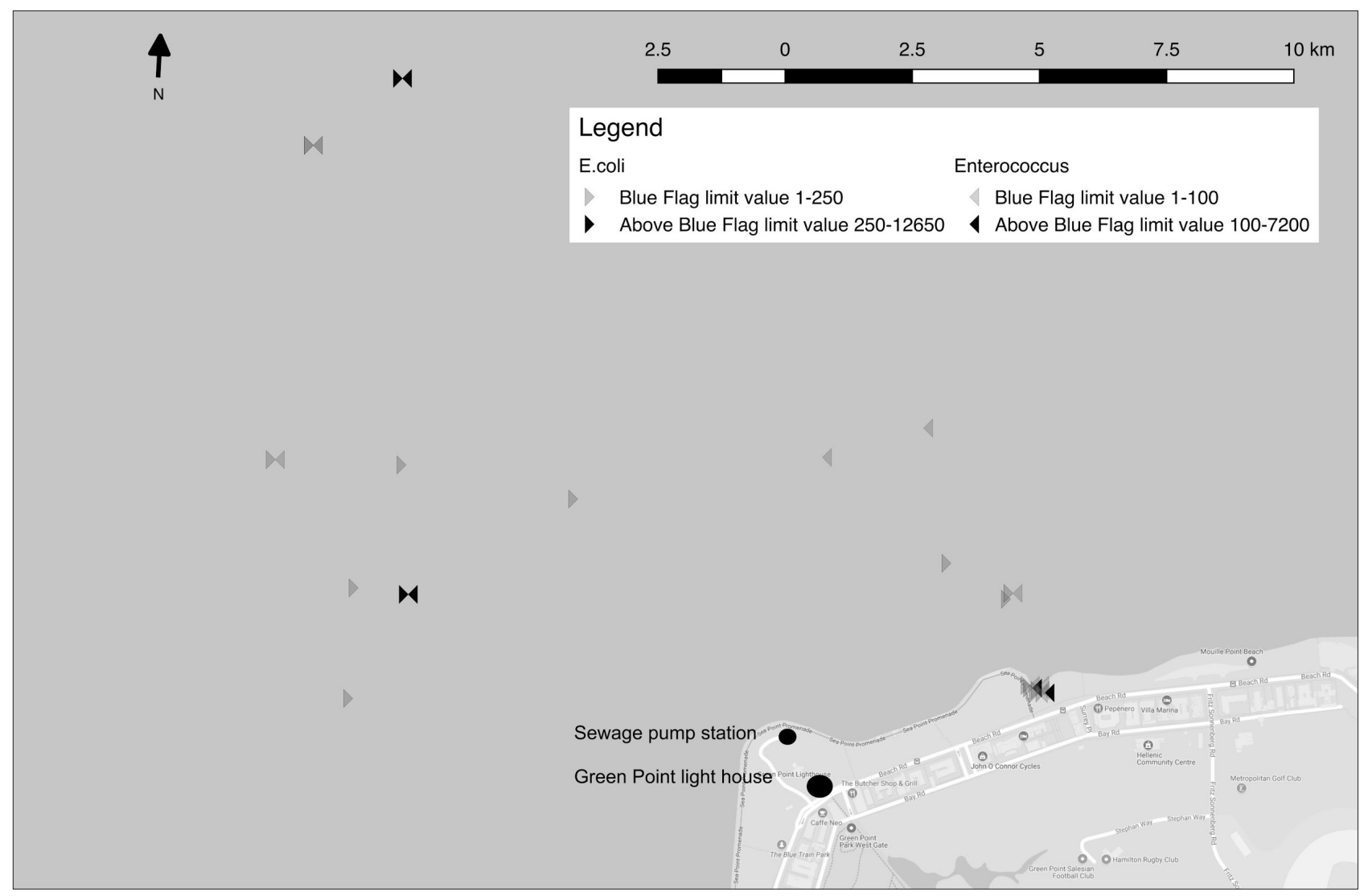

Figure 1: Location of sampling and microbial load of seawater and beach water (Granger Bay, Cape Town). 
Predictive modelling is consistent with South Africa's policy for the disposal of land-derived wastewater in the sea, published in $2006 .{ }^{17}$

Because seawater is constantly in a state of movement we also investigated the presence in marine organisms of compounds that could only come from long-term exposure to sewage-contaminated seawater. A variety of species was collected from rock pools at low tide near Granger Bay (Figure 1).

\section{Bioaccumulation of persistent organic pollutants in marine organisms}

The selection of compounds for this study was based on their known persistence in the environment as well the availability of testing protocols and standards. The compounds tested for included perfluorinated compounds and a variety of pharmaceuticals, a cleaning agent, caffeine and bisphenol $\mathrm{A}$.

Caffeine (Ca) was chosen as a broad indicator of faecal contamination. Caffeine passes from the human digestive system via faeces into the environment in unmodified form. Perfluorinated compounds are a large family of synthetic chemicals, broadly used in industrial and consumer products. They are used as industrial surfactants and surface protectors for food containers, paper, leather, carpet, fabric coating and firefighting foams because of their water and oil repelling ability. Perfluorinated compounds selected here include perfluorooctanoic acid (PFOA), perfluoroheptanoic acid (PFHpA), perfluorononanoic acid (PFNA), perfluorodecanoic acid (PFDA) and perfluoroundecanoic acid (PFUnDA). Pharmaceuticals tested for were acetaminophen (ACT), diclofenac (DSS), lamivudine (LA), phenytoin (PHE), carbamazepine (CAR) and sulfamethoxazole (SUL). The household product tested for was triclosan. Triclosan (TS) is an antibacterial and antifungal agent commonly found in household and personal cleaning products including some toothpastes. The industrial chemical tested for was bisphenol A (BPA), which is an organic synthetic compound that mimics oestrogen and is used in plastics, the lining of some food and beverage cans and thermal paper used in point-of-payment slips.

\section{Sample collection and handling}

Limpet (Patella vulgata), mussel (Mytilus galloprovincialis), sea urchin (Tripneustes ventricosus), starfish (Fromia monilis), sea snail (Tegula funebralis) and seaweed (Ulva lactuca) samples were collected from rock pools along the shoreline near Granger Bay in 2017. In 2015, samples were collected at a depth of $\sim 30 \mathrm{~m}$ in the ocean close to the marine outfall diffusers. Samples were wrapped in foil and stored on ice for transportation to the laboratory. All marine organism samples were delivered to the laboratory within $1 \mathrm{~h}$ of collection, and stored at $-20^{\circ} \mathrm{C}$ at the laboratory. The samples were analysed according to the protocols below.

\section{Analytical protocols}

All sample bottles, extraction and volumetric flasks used were washed in methanol, rinsed with tap water and deionised water, then air dried.

\section{Reagents}

Methanol, acetonitrile and acetone were HPLC grade. The standards, purchased from Sigma Aldrich (Johannesburg, South Africa), were: perfluorooctanoic acid (PFOA 96\%), perfluoroheptanoic acid (PFHpA 99\%), perfluorononanoic acid (PFNA 97\%), perfluorodecanoic acid (PFDA 98\%), perfluoroundecanoic acid (PFUnDA 95\%), bisphenol A $(\geq 99 \%)$, acetaminophen $(\geq 99 \%)$, caffeine, ibuprofen sodium salt $(\geq 98 \%)$, diclofenac sodium salt, lamivudine ( $\geq 98 \%)$, triclosan ( $\geq 97 \%)$, phenytoin, sulfamethoxazole ( $\geq 97 \%$ ), sulfisoxazole ( $\geq 99 \%)$ and acetaminophen- $d_{4}(\geq 97 \%)$. Ultrapure water was purified using a Milli-Q system (Millipore, Bedford, MA, USA).

Primary stock solutions of individual analytes were prepared in methanol at a concentration of $1000 \mu \mathrm{g} / \mathrm{mL}$ and appropriately diluted in methanol.
Sample preparation: Extraction and clean-up

In this study, Oasis HLB was selected over Strata $X$ cartridge for sample extraction. ${ }^{18}$

\section{Water samples}

Seawater samples of $500 \mathrm{~mL}$ were extracted based on the method used by Valdés et al. ${ }^{19}$, with some modifications. The extract was concentrated to $2 \mathrm{~mL}$ under a gentle nitrogen stream and then transferred to amber vials and centrifuged for 25 min prior to analysis.

\section{$\underline{\text { Tissue samples }}$}

Tissue from marine organisms was freeze dried and ground into a fine powder. Approximately $10 \mathrm{~g}$ was weighed and placed into an extraction thimble. Surrogates (sulfisoxazole, acetaminophen- $d_{4}$ ) were added to each sample. The mixture was extracted with $100 \mathrm{~mL}$ methanol/ acetone $3: 1(\mathrm{v} / \mathrm{v})$. The extract was concentrated to $10 \mathrm{~mL}$ using a rotary evaporator at reduced pressure, and the sample $\mathrm{pH}$ was adjusted to 6 by adding $1 \mathrm{M} \mathrm{NaOH}$ or $\mathrm{HCl}$ so as to allow the precipitation of lipids. The extract was centrifuged at $3000 \mathrm{rpm}$ for $20 \mathrm{~min}$. The supernatant was transferred to glass bottles and Millipore water was added to make up to a volume of $100 \mathrm{~mL}$. These aqueous extracts were further extracted and cleaned using the procedure of Valdés et al. ${ }^{19}$ for seawater samples. The final eluate was concentrated under nitrogen and then reconstituted to $2 \mathrm{~mL}$ with methanol. Recovery standards were added to each sample prior to analysis.

\section{Chromatographic conditions}

The chromatographic separations were performed with the Acquity UPLC $^{\text {TM }}$ (Waters, Milford, MA, USA). Simultaneous determination of all the compounds of interest was achieved using an Acquity UPLC BEH C18 1.7- $\mu \mathrm{m}$ column $(2.1 \mathrm{~mm} \times 1000 \mathrm{~mm})$ with an Acquity BEH C18 $1.7-\mu \mathrm{m}$ VanGuard ${ }^{\mathrm{TM}}$ precolumn $(2.1 \mathrm{~mm} \times 5 \mathrm{~mm})$, supplied by Waters. The column temperature was set to $50^{\circ} \mathrm{C}$. The mobile phase consisted of a mixture of $0.02 \mathrm{M}$ formic acid (solvent $\mathrm{A}$ ) in water and acetonitrile (solvent B). Linear gradient elution of $0.35 \mathrm{~mL} / \mathrm{min}$ was used starting with a mixture of $80 \%$ solvent $A$ and $20 \%$ solvent B for 9 min. At 10 min, the acetonitrile percentage was increased linearly from $90 \%$ to $100 \%$ and was later maintained at $80 \%$ of solvent $A$ and $20 \%$ of solvent B. A volume of $5 \mu \mathrm{L}$ of each sample was injected into the LC/MS system. Standards and the test samples were subjected to a 12-min chromatographic run.

\section{Mass spectrometry}

The UPLC was coupled to a triple quadrupole mass spectrometer (Xevo TQ-MS), with an electrospray ionisation source. During optimisation, a multiple reaction monitoring scan mode was generated for all analytes. In addition, for maximum sensitivity, other conditions such as source temperature, capillary voltage, cone voltage, cone gas flows and desolution temperatures were standardised. This standardisation was achieved by direct injection of stock solutions with a concentration of $10 \mu \mathrm{g} / \mathrm{mL}$. A capillary voltage of $3.5 \mathrm{kV}$, desolvation gas $\left(\mathrm{N}_{2}\right)$ flow of $800 \mathrm{~L} / \mathrm{h}$, source temperature of $140{ }^{\circ} \mathrm{C}$ and desolvation temperature of $400{ }^{\circ} \mathrm{C}$ were finally used. The analytical operation control and data processing were performed with Masslynx software.

\section{Method modification, validation, quality control and calibration}

The volume of each water sample used for the extraction technique was increased from $250 \mathrm{~mL}$ to $500 \mathrm{~mL}$. To ascertain the concentration and consistency in the extraction technique for all the analytes, each extraction round was triplicated. The analytical method was validated using EU Commission Decision 2002/657/EC as a guideline. To show the applicability of the analytical method, a validation study was carried out. The validation procedure included the assessment of method linearity, specificity/selectivity, precision, recovery and calculation of the limits of detection and quantification. Six-point calibration curves were constructed (four replicates). The multi-matrix capacity of the analytical technique was checked with an identical validation study using ultrapure water and seawater. To monitor for potential contamination, blank samples of ultrapure water were extracted and analysed along with 
the seawater samples and laboratory spikes. Methanol blanks were also run between samples in order to monitor for instrumental contamination and carry-over. None of the compounds of interest was detected in the ultrapure water and reagents used. Chromatographic peak area, signal noise and height were used to define and quantify the analytes of interest. Calibration standards were analysed prior to each analysis batch. The final analyte concentration was calculated as follows:

initial concentration $x$ sample volume injected

Final analyte concentration $=\frac{\text { sample volume extracted }}{\text { s. }}$

\section{Findings: Organic pollutants in marine organisms and seawater}

All 15 indicator chemical compounds were present in the seawater samples in trace concentrations (Figures 2 to 4 ) and considerably higher levels were present in limpets (Patella vulgata), mussels (Mytilus galloprovincialis), sea urchins (Tripneustes ventricosus), starfish (Fromia monilis), sea snails (Tegula funebralis), seaweed (U/va lactuca) and sediment samples (Figures 5 to 7 ). The high levels of all the chemical compounds in marine organisms are evidence of bioaccumulation over time as the organisms have no way of escaping the pervasive presence of these chemicals in the seawater. The significant increase in their levels in 2017 against our findings of 2015 (Figure 8) is noteworthy. None of these compounds would normally be found in seawater and should definitely not be present in these marine organisms. With the exception of caffeine, all are manufactured substances. The finding that all 15 tested compounds were present in every organism and in the background sediments and seaweed tested, is a clear indication of faecal pollution of the shoreline, and that additional chemical substances are likely present in the seawater and thus in the marine organisms.

\section{Discussion}

Pharmacological compounds such as the analgesic and anti-inflammatory drugs acetaminophen (also known as paracetamol) and diclofenac, the anti-seizure medication phenytoin, the antibiotic sulfamethoxazole and the antiretroviral lamivudine are made to be stable and effective at low doses. They are polar, lipophilic, soluble and nonvolatile compounds..$^{20}$ For these reasons, many pharmaceutical compounds or secondary metabolites do not decompose, but survive in the environment to become persistent organic pollutants. Unknown quantities of partially metabolised drugs which may be toxic are also released in faeces and urine. ${ }^{21}$ Their molecular sizes in the nanometre $\left(10^{-9}\right)$ and Angstrom range $\left(10^{-10}\right)$ make it impossible for marine organisms to exclude them. It has been widely reported that these compounds are continuously released into the environment, ${ }^{22-24}$ and bioaccumulate in wild-caught fish populations at concentrations of nanograms per gram. ${ }^{25,26}$ Huerta et al. ${ }^{25}$ showed that diclofenac and carbamazepine were the most highly bioaccumulated at $18.8 \mathrm{ng} / \mathrm{g}$ in fish liver. Current regulations do not specify that they should be monitored in our water supplies or in sewage effluents (South African National Drinking Water Standard (SANS) 241: 2015), even though Patterton's study ${ }^{11}$ demonstrated their presence in South African tap water. Moreover, it is known that disinfectants and antibiotics cause selection for resistance in the gene pool of microorganisms, ultimately making them impervious to the antibiotic or antimicrobial agents. ${ }^{27}$

The full impact of constant, low-grade, chronic exposure to a plethora of pharmaceuticals, antibiotics and cleaning products on marine organisms, the marine food chain, and human health is not yet fully known, but their ubiquitous presence in trace levels in the desalination intake water poses a potential risk to human health.

Although some pharmaceuticals are unlikely to constitute a risk to humans as they are found in low concentrations and have a low toxicity, such as iopromide ${ }^{28}$, other pharmaceuticals such as natural and synthetic sex hormones pose considerable risks to the aquatic environment ${ }^{29}$.

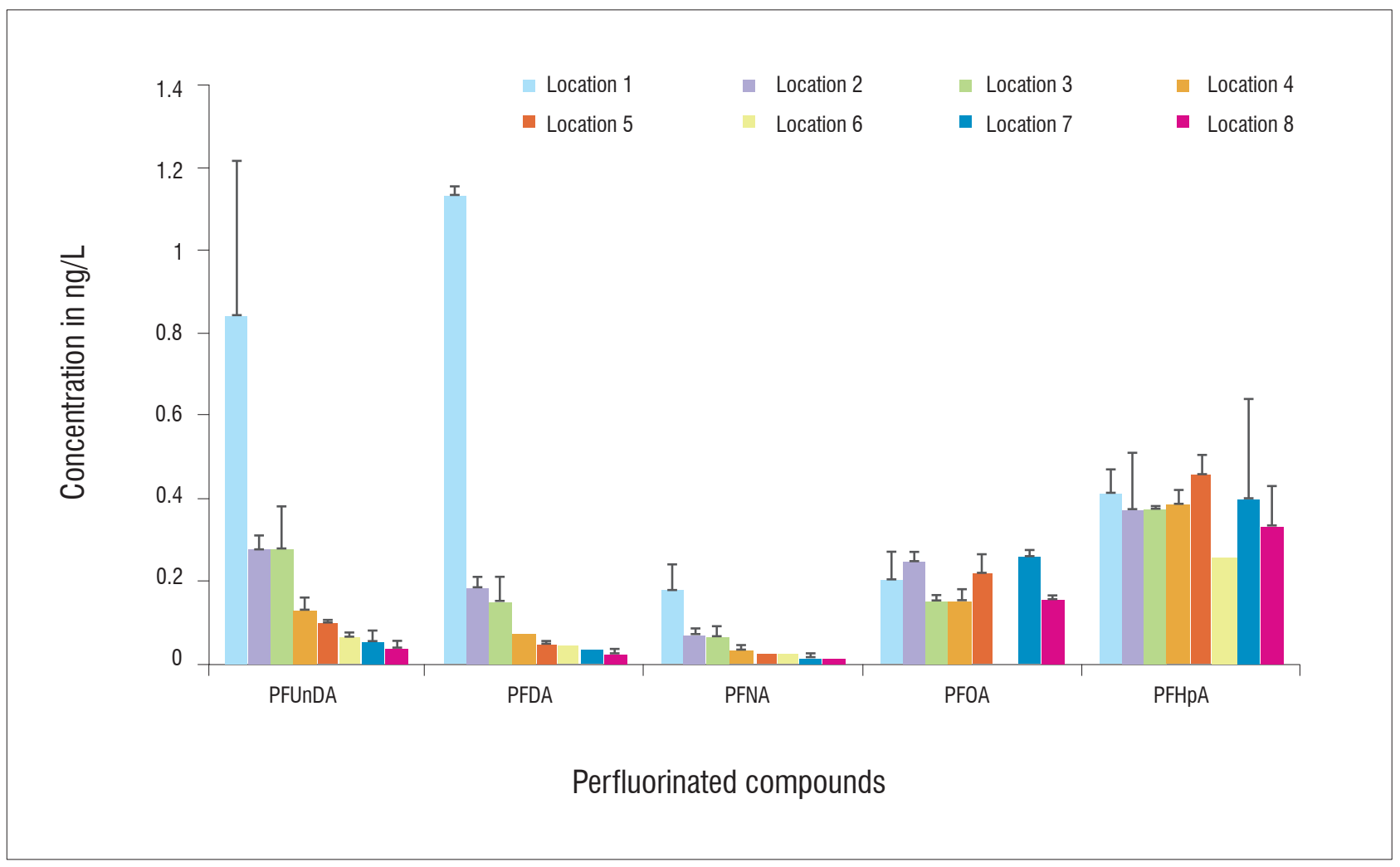

PFUnDA, perfluoroundecanoic acid; PFDA, perfluorodecanoic acid; PFNA, perfluorononanoic acid; PFOA, perfluorooctanoic acid; PFHpA, perfluoroheptanoic acid

Figure 2: Concentration of perfluorinated compounds in seawater samples collected off Granger Bay, Cape Town. 


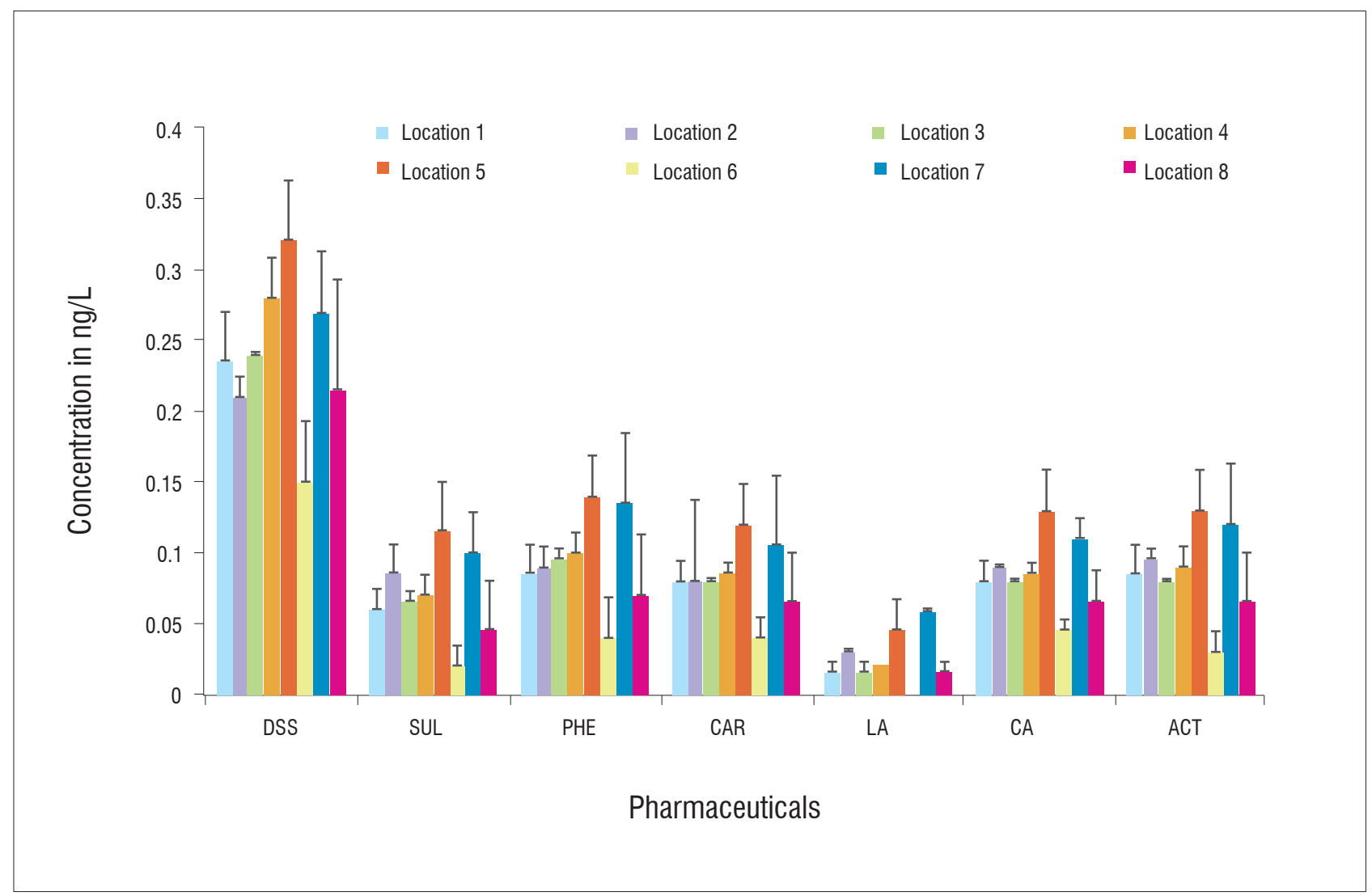

DSS, diclofenac; SUL, sulfamethoxazole; PHE, phenytoin; CAR, carbamazepine; LA, lamivudine; CA, caffeine; ACT, acetaminophen

Figure 3: Concentration of pharmaceuticals in seawater samples collected off Granger Bay, Cape Town.

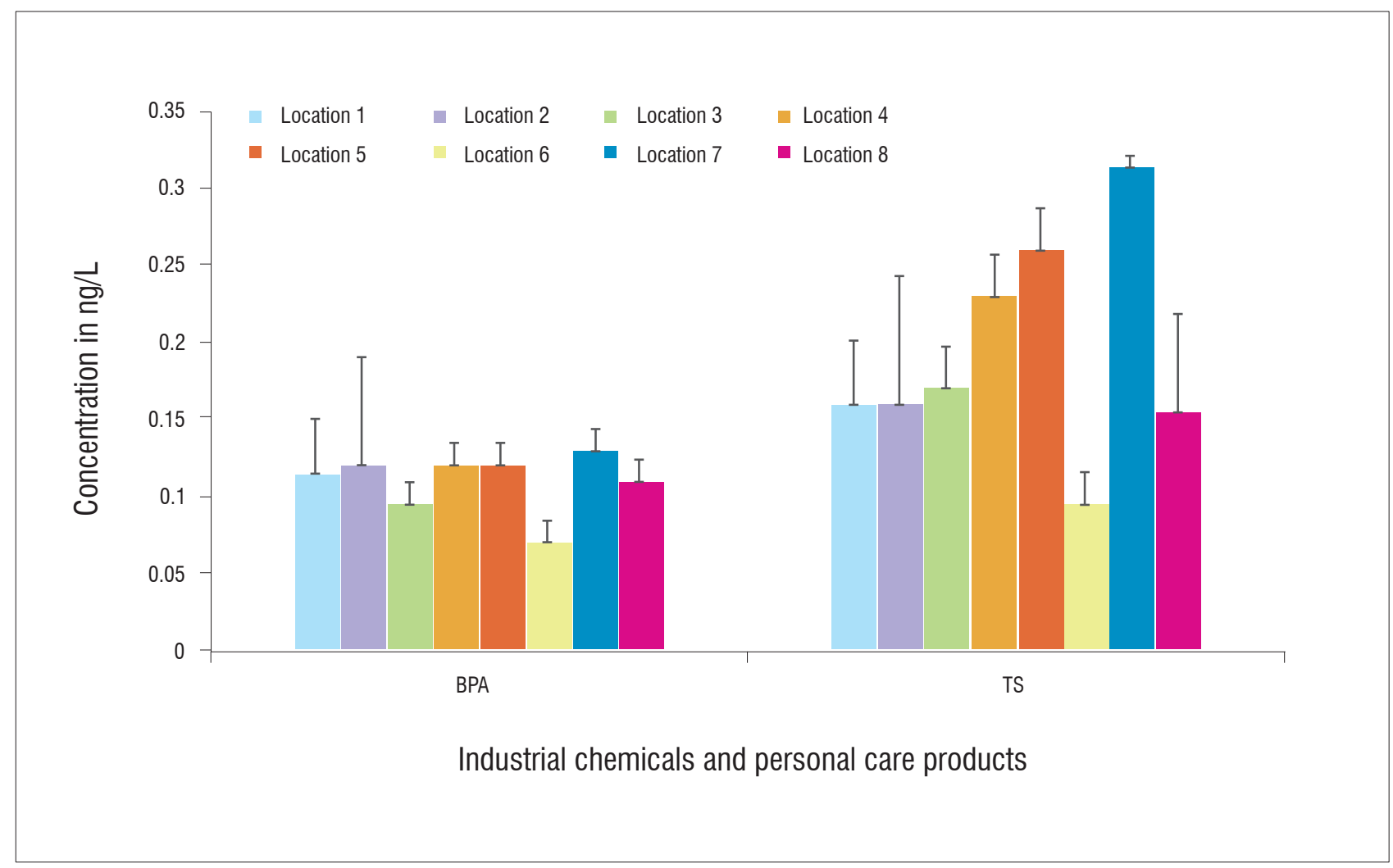

BPA, bisphenol A; TS, triclosan

Figure 4: Concentration of industrial and household chemicals in seawater samples collected off Granger Bay, Cape Town. 


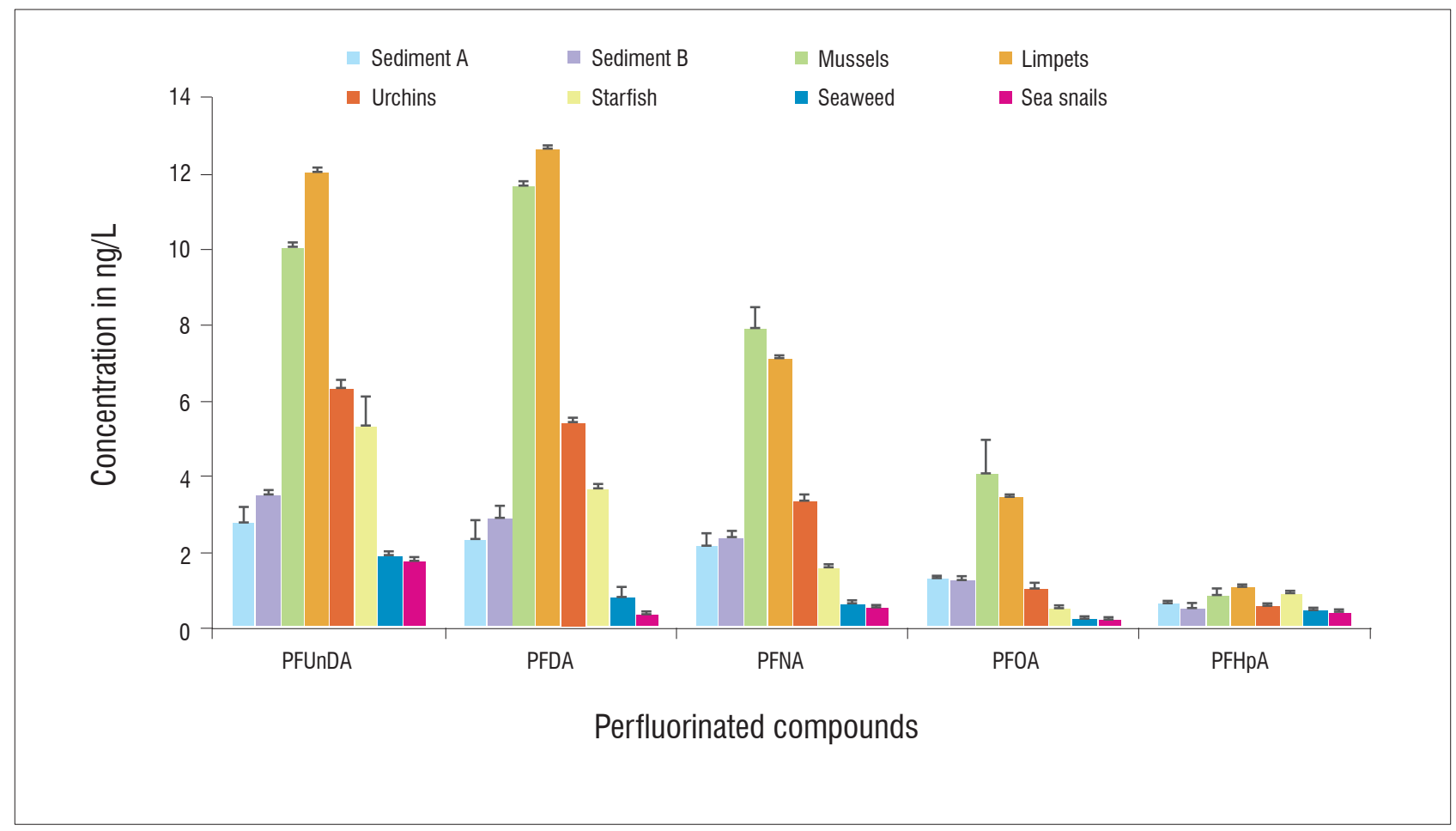

PFUnDA, perfluoroundecanoic acid; PFDA, perfluorodecanoic acid; PFNA, perfluorononanoic acid; PFOA, perfluorooctanoic acid; PFHpA, perfluoroheptanoic acid Note: Sediment $A$ is from wet beach sand and Sediment $B$ from where the organisms were found.

Figure 5: Concentration of perfluorinated compounds in marine organisms and sediments from the shores near Granger Bay, Cape Town.

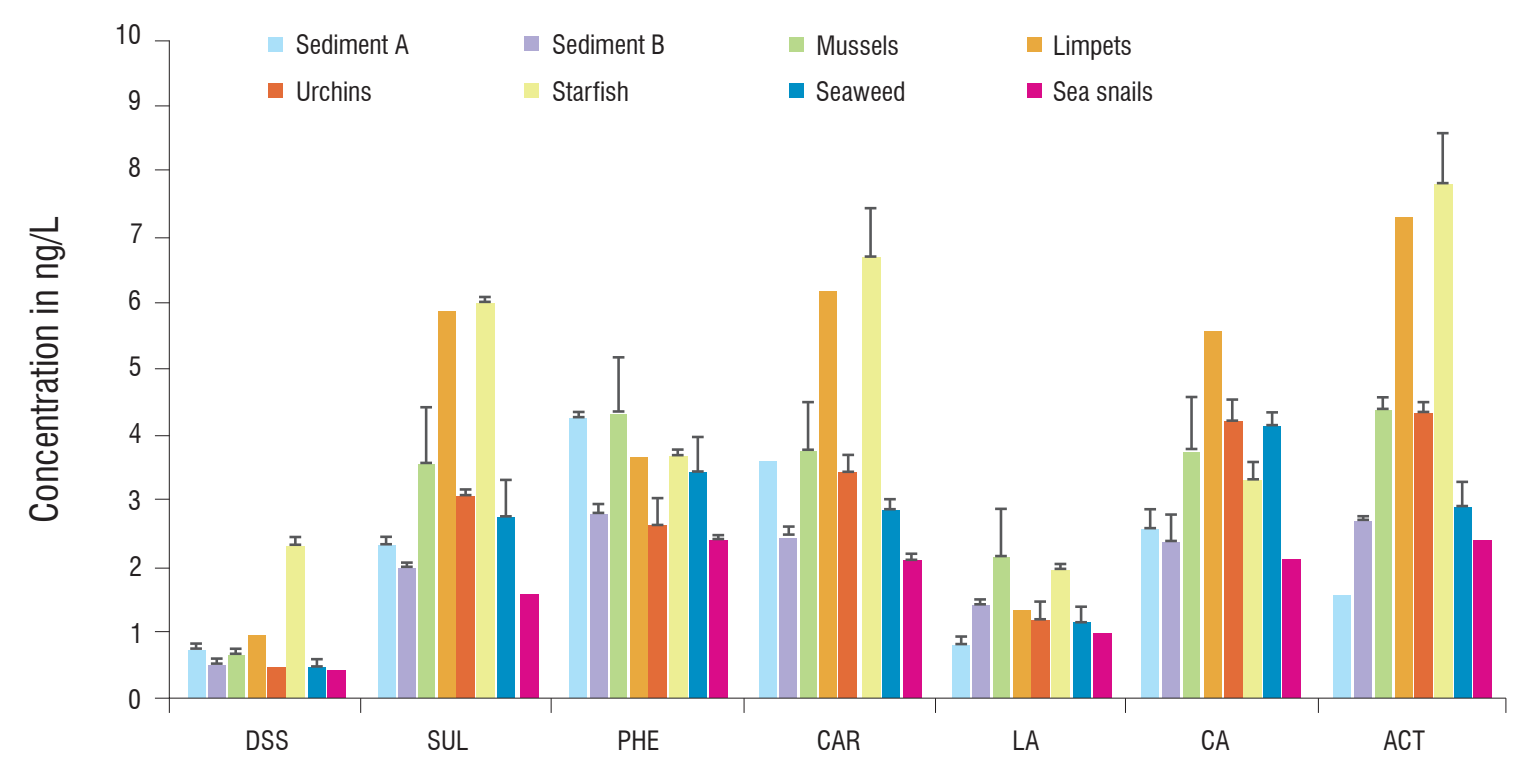

Pharmaceuticals

DSS, diclofenac; SUL, sulfamethoxazole; PHE, phenytoin; CAR, carbamazepine; LA, lamivudine; CA, caffeine; ACT, acetaminophen Note: Sediment $A$ is from wet beach sand and Sediment $B$ from where the organisms were found.

Figure 6: Concentration of pharmaceuticals in marine organisms and sediments from the shores near Granger Bay, Cape Town. 


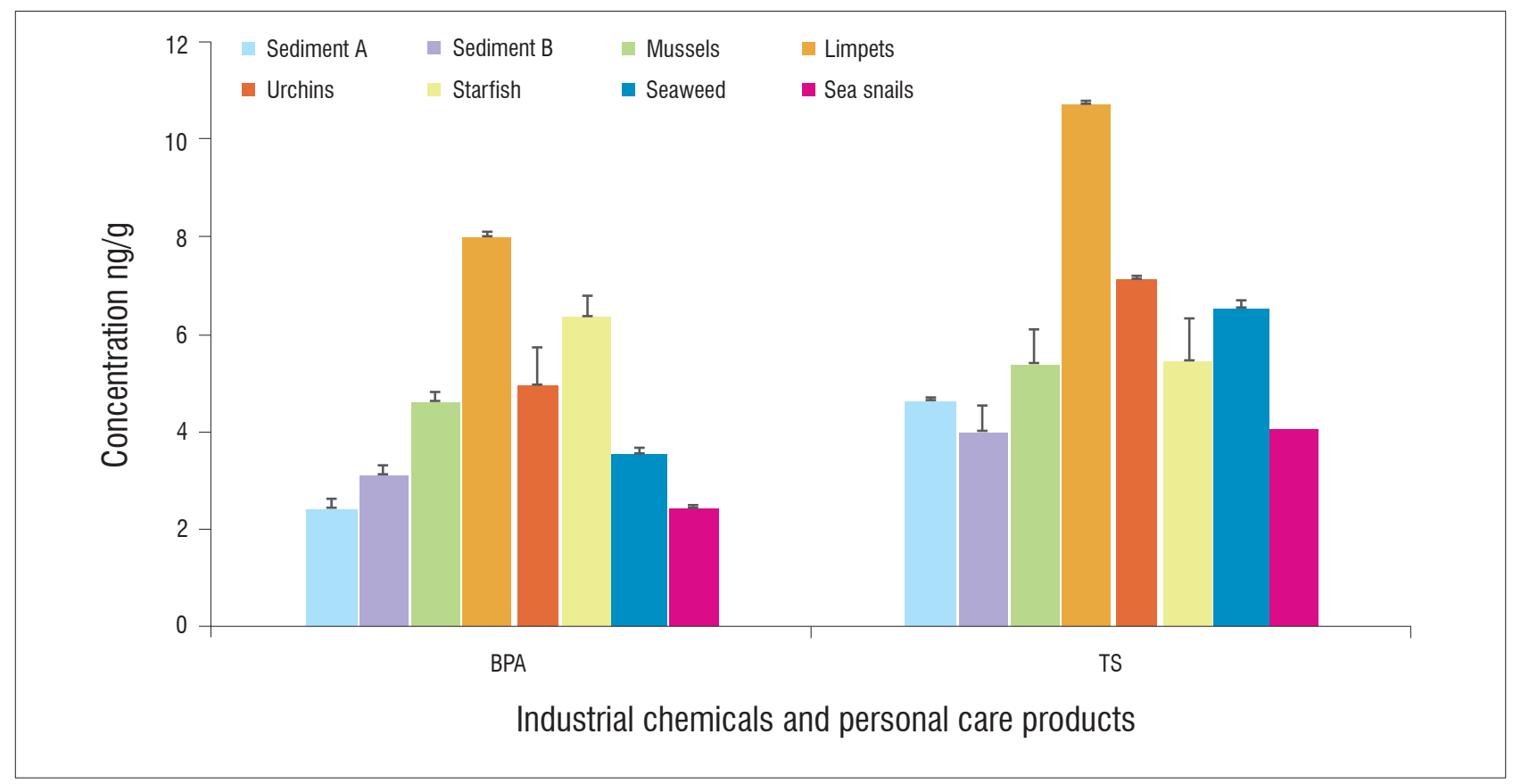

BPA, bisphenol A; TS, triclosan

Note: Sediment $A$ is from wet beach sand and Sediment $B$ from where the organisms were found.

Figure 7: Concentration of industrial and household chemicals in marine organisms and sediment from the shores near Granger Bay, Cape Town.

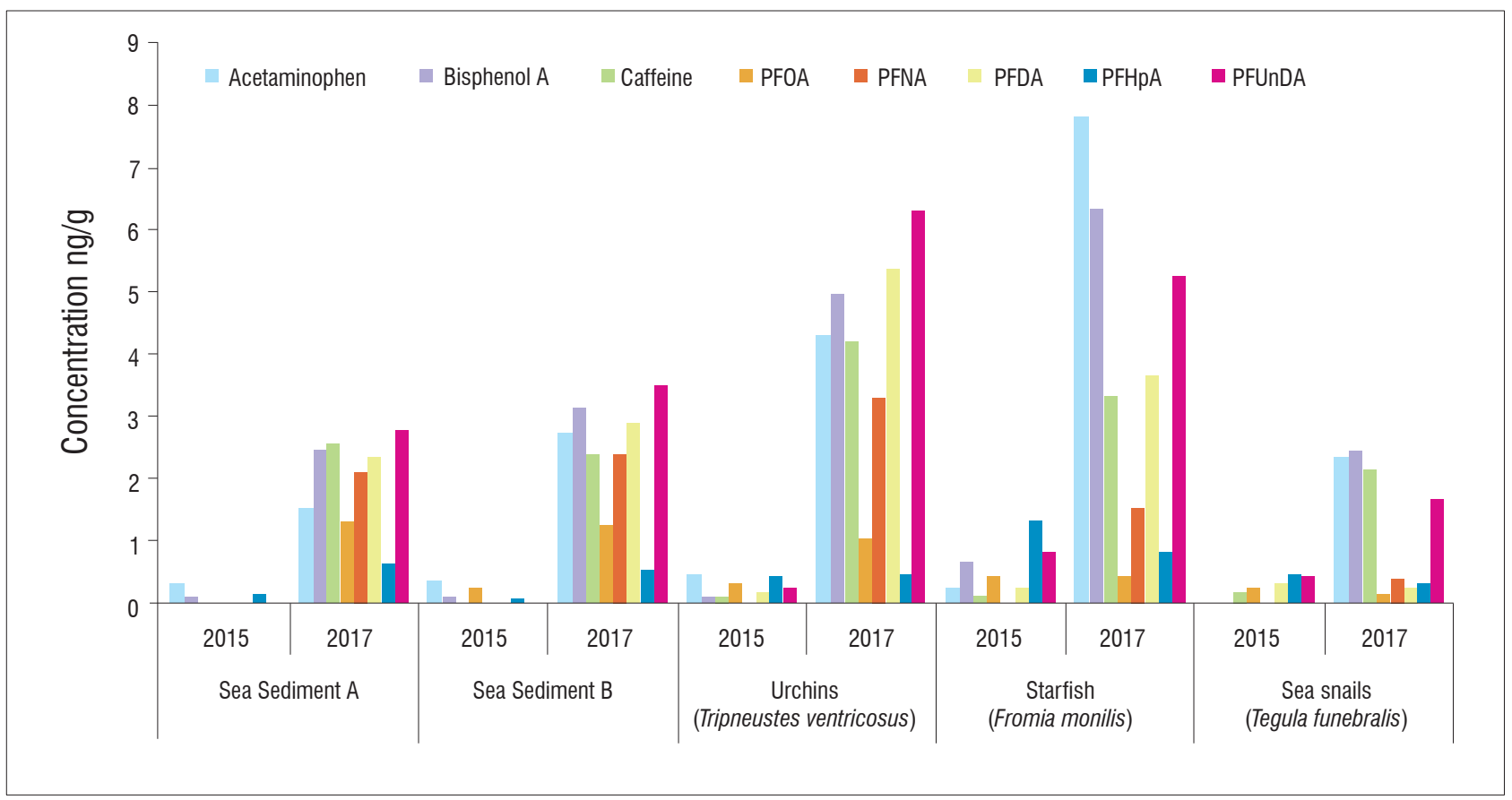

PFOA, perfluorooctanoic acid; PFNA, perfluorononanoic acid; PFDA, perfluorodecanoic acid; PFHDA, perfluoroheptanoic acid; PFUnDA, perfluoroundecanoic acid

Figure 8: The difference in the level of selected compounds in marine organisms sampled in July 2015 and July 2017.

Even where seafood accounts for only about $10 \%$ of the diet, it has been shown to be one of the main routes by which chemical contaminants find their way into human tissues ${ }^{30}$, which in turn may be deleterious to human health. Moreover, the synergetic effects of pharmaceuticals and other compounds on living organisms are unknown. ${ }^{31}$

Drinking water supplies from the seawater desalination plants should be carefully tested for toxicity, which need not be costly. ${ }^{13,32}$ Apart from the many compounds present in seawater, industrial effluents as well as hydrocarbon pollution as a result of shipping, pleasure craft and harbour effluents also impact intake water. Natural incidences such as red tide or harmful algal blooms have also been linked to marine sewage outfalls, ${ }^{33-35}$ which could also impact the quality of intake water. As their combined effects and concentrations are mostly unknown, the precautionary principle should be followed with regard to sewage disposal into the environment. Formation of chlorine disinfection byproducts such as inorganic chloramines, organohaloginated byproducts and trichloroamines should also be monitored and removed from the recovered water. ${ }^{13}$ 


\section{Conclusions}

\section{Implications of findings for desalination}

Apart from the high microbial load being discharged into the ocean daily, the complexity and toxicity of chemicals that are being disposed into the City's sewage are imposing a growing chemical pollution risk to the nearshore coastal environment, and thus to the desalination plant's intake water. Given the diversity of contaminants shown to be ubiquitously present in the intake water in such close proximity to the marine outfall in Green Point, it is probable that the water recovered from desalination may still be contaminated with traces of complex pollutants after the reverse osmosis process, as Patterton's ${ }^{11}$ study also showed. This probability represents a public health issue. Drinking water supplied by the seawater desalination plants should be regularly screened for its toxicity. Adequate disinfection and monitoring of the efficacy of tertiary treatment to ensure complete decomposition of harmful pharmaceuticals and other chemicals is essential to ensure that the water supplied to the City is not toxic. Screening for specific compounds is very costly but toxicity tests give rapid results. ${ }^{13,32}$

Even if most of the compounds were removed by the reverse osmosis step, they are not destroyed and remain in the brine retentate; returning these compounds in the brine retentate to the sea as is planned, only to be filtered indefinitely while toxic compounds build up in marine life, is a futile exercise.

In the long term, it would be technically more efficient and cost-effective to prevent the sewage from entering the ocean in the first place. Moreover, desalination intake water treatment and sewage treatment should include a tertiary stage of combined advanced oxidation, capable of fully decomposing pharmaceutical compounds. In the best performing wastewater treatment plant for potable reuse of sewage that has been studied in the Western Cape region, the treatment train was composed of a modern dual-membrane treatment process..$^{13}$ The membrane system received secondary treated wastewater from a treatment train comprised of a conventional activated sludge treatment process with an optional chemical phosphate removal after chlorination. The secondary treated wastewater entered the water recovery plant where it was treated using a sand filter, ultrafiltration membrane, reverse osmosis membranes and, finally, with advanced oxidation including ultraviolet (UV) light and hydrogen peroxide before being blended with conventionally treated water and distributed. This system currently allows direct potable reuse of sewage and is already operational in the region. This type of system may be able to provide potable water of reasonable quality from wastewater but the water from this well-operated plant was still not passing Ames mutagenicity and oestrogen mimicry tests for toxicity in our previous study. ${ }^{13}$ With a rise in the use of chemical compounds on a daily basis, and many thousands of regulated and unregulated emerging contaminants being discharged and detected in the aquatic environment, many of which exceed the recommended reference dose $(\mathrm{mg} / \mathrm{kg} /$ day) of various regulators ${ }^{13}$, great caution is needed. Implementation of barriers, monitoring programmes and assessment programmes to eliminate or minimise these risks is essential.

Compact, new treatment systems that can treat the sewage to high standards and recover the water before discharge to the ocean can eliminate the need for desalination. Advanced oxidation systems include ozonation ${ }^{36}$, ozone/hydrogen peroxide ${ }^{37,38}$, ozone/UV ${ }^{39}$, hydrogen peroxide/UV ${ }^{40}, \mathrm{UV} /$ chlorine $^{41-43}, \mathrm{UV} / \mathrm{TiO}_{2}{ }^{44}$, ultrasonic irradiation ${ }^{45}$ or sonolysis 46,47 , photocatalysis ${ }^{48,49}$, photo fentons ${ }^{50}$, dielectric barrier discharge ${ }^{51,52}$ and electrochemical ${ }^{53}$ reactions, which all work by producing short-lived but highly reactive free radicals and have been used most effectively in combined systems for the degradation or destruction of complex organic compounds in water. A thorough investigation is needed in the Western Cape on viable advanced oxidation technologies to add to the conventional treatment train of coagulation, flocculation, adsorption, precipitation, reverse osmosis, membrane bioreactors, nanofiltration and electrodialysis, recognising that the treatment of sewage and wastes is just as important to public health as the supply of fresh water is.

\section{Implications for the City of Cape Town}

The idea of sending a sewer pipeline out to sea was approved when the volumes of effluent being discharged to the ocean were relatively small, based on the incorrect assumption that 'the solution to pollution is dilution', and at a time when the variety and volume of manufactured chemicals and pharmacological compounds impacting the sewage was far lower than is the current situation.

\section{Pipeline extension}

These findings demonstrate that the assumptions behind marine sewage outfalls are incorrect and outdated. Extending the pipeline out to sea will not solve the problem, as it is clear that, under certain conditions, sewage flows back to shore in quantities that are harmful, and toxic chemicals will be released, albeit further from the shore, impacting marine life.

\section{Predictive modelling}

Until the sewer outfall is replaced, predictive modelling based on daily weather and sea conditions offers a better tool for seawater quality and beach management than sample-based monitoring. Much of the information that is required for predictive modelling is already being collected daily by ocean users who have set up WindGuru stations or similar, and who would actively participate in a citizen science project. A study consolidating such data with daily water samples is needed.

\section{The precautionary principle}

The measurable presence of indicator organisms and indicator chemicals points to the presence of pathogens and many other persistent chemicals in our ocean. The potential for their bioaccummulation is demonstrated. Because of the hazards of these compounds, the precautionary principle is highly relevant in terms of human health. Should desalination of seawater be the main option for augmenting potable water supplies, the health risks of pharmacological and chemical compound accumulation need to be quantified by daily monitoring and mitigated prior to the release of the water into the potable water reticulation system. An example of such a monitoring system is the Windhoek reclamation system. Testing the provided water to South African National Drinking Water Standard (SANS) 241: 2015 is not adequate as these compounds are not yet regulated.

\section{The 'polluter pays principle'}

In terms of the 'polluter pays principle', the costs of the chemical and pharmaceutical compound clean-up ought to be borne by the companies producing the substances. Pharmaceutical and chemical companies are among the wealthiest multinational corporations globally. While air polluters are required to ensure emissions are cleaned from the commons that is the air breathed by all, pharmaceutical companies and the chemical industry have not been contributing to the clean-up of pollutants in water systems.

\section{Purchasing power}

Retailers and consumers of pharmaceuticals and common household chemicals need to review their contribution to the growing pollution of ocean ecologies. Our individual decisions have a huge collective impact.

\section{Politics of water, environment and sanitation}

Historically, cities were made possible by the development of infrastructure to adequately manage human waste. The City of Cape Town has outgrown its current water supply and sanitation infrastructure. ${ }^{54}$ While the City has vigorously opposed the politics of the 'poo flingers' such as Andile Lili who have dumped human waste to force the argument about improved sanitation in Khayelitsha and elsewhere, the City itself is daily depositing a volume of many Olympic-size swimming pools into the ocean. One might indeed quip that in terms of the current sewage management infrastructure, 'Je suis Andile Lili'. The convergence of sanitation activism in seaside suburbs and shack settlements in a time of drought suggests that the City's water should be understood as one 
hydrological system, and therefore managed as a single ecology, not via the separation of environment, sanitation and water supply.

\section{Acknowledgements}

We gratefully acknowledge funding from the National Research Foundation (South Africa) for the Human Social Dynamics Grant (HSD141104109103 Grant 96035 titled Race and the Making of an Environmental Public) to Environmental Humanities South at the University of Cape Town. We are indebted to Tracy Fincham and Billy Fisher at Kaskazi Kayaks for guiding the sampling team and for the use of kayaks; to the SABS Rosebank for E. coli and Enterococcus results; to the laboratories at Stellenbosch University and the University of the Western Cape for the CAF results; and to Nicholas Lindenberg for assistance with the map.

\section{References}

1. Zackon M. Public protest and the production of evidence regarding Cape Town's marine sewer outfalls [honour's dissertation]. Cape Town: University of Cape Town; 2017.

2. Jackson M. Bay of sewage [video on the Internet]. c2016 [cited 2017 Nov 01]. Available from: https://www.youtube.com/watch?v=tEh5JpoH9qo

3. Weimann E. Blue Flag beaches: Bathers at risk for thalassogenic diseases. J Env Ecol. 2014;5(1), Art. \#5773, 8 pages. http://dx.doi.org/10.5296/jee. v5i1.5773

4. Yu Y, Huang Q, Cui J, Zhang K. Determination of pharmaceuticals, steroid hormones and endocrine-disrupting personal care products in sewage sludge by ultra-high-performance liquid chromatography-tandem mass spectrometry. Anal Biochem. 2011;399:891-902. https://doi.org/10.1007/ s00216-010-4295-2

5. Ternes TA, Siegrist H. Scrutinizing pharmaceuticals and personal care products in wastewater treatment. Environ Sci Technol. 2004;38:392A-399A. https://doi.org/10.1021/es040639t

6. Tijani J0, Fatoba 00, Babajide 00, Petrik LF. Pharmaceuticals, endocrine disruptors, personal care products, nanomaterials and perfluorinated pollutants: A review. Environ Chem Lett. 2016;14:27-49. https://doi. org/10.1007/s10311-015-0537-z

7. Oaks JL, Gilbert M, Virani MZ, Watson RT, Meteyer CU, Rideout BA, et al. Diclofenac residues as the cause of vulture population decline in Pakistan. Nature. 2004;427:630-633. https://doi.org/10.1038/nature02317

8. Lange R, Hutchinson TH, Croudace CP, Siegmund F, Schweinfurth H, Hampe $P$, et al. Effects of the synthetic estrogen 17 alpha-ethinylestradiol on the life cycle of the fathead minnow. Environ Toxicol Chem. 2001;20(6):1216-1227. https://doi.org/10.1002/etc.5620200610

9. Boxall ABA, Kolpin DW, Halling-Sorensen B, Tolls J. Are veterinary medicines causing environmental risks? Environ Sci Technol. 2003;37:286A-294A. https://doi.org/10.1021/es032519b

10. Ncube EJ, Voyi K, Du Preez H. Implementing a protocol for selection and prioritisation of organic contaminants in the drinking water value chain: Case study of Rand Water, South Africa. Water SA. 2012;38(4):487-503. https:// doi.org/10.4314/wsa.v38i4.3

11. Patterton HG. Scoping study and research strategy development on currently known and emerging contaminants influencing drinking water quality. WRC report no. 2093/1/13. Pretoria: WRC; 2013.

12. Osunmakinde CS, Tshabalala OS, Dube S, Nindi MM. Verification and validation of analytical methods for testing the levels of PPHCPs (pharmaceutical \& personal health care products) in treated drinking water and sewage. WRC report no. 2094/1/13. Pretoria: WRC; 2013.

13. Swartz CD, Genthe B, Chamier J, Petrik LF, Tijani JO, Adeleye AP, et al. Emerging contaminants in wastewater treated for direct potable re-use: The human health risk priorities in South Africa. WRC project no. K5/2369. Pretoria: WRC; 2016.

14. Blue Flag beach criteria and explanatory notes [document on the Internet]. No date [cited 2017 Jan 02]. Available from: https://static1.squarespace. com/static/55371ebde4b0e49a1e2ee9f6/t/56cc2a59859fd03db ee43223/1456220762132/Beach+Criteria + and + Explanatory+Notes.pdf
15. Olyphant GA, Whitman RL. Elements of a predictive model for determining beach closures on a real time basis. Environ Monit Assess. 2004;98(13):175-190.

16. Frick WE, Zepp RG. Nowcasting and forecasting concentrations of biological contaminants at beaches. Environ Sci Technol. 2008;42(13):4818-4824. https://doi.org/10.1021/es703185p

17. Taljaard S, Viljoen WAMP. Operational policy for disposal of land-derived wastewater to the marine environment of South Africa. Water SA. 2006;32(4) 527-533.

18. Adeleye AP. Perfluorinated compounds, bisphenol A and acetaminophen in selected wastewater treatment plants in and around Cape Town, South Africa [master's thesis]. Cape Town: Cape Peninsula University of Technology; 2016.

19. Valdés ME, Amé MV, Bistoni MD, Wunderlin DA. Occurrence and bioaccumulation of pharmaceuticals in a fish species inhabiting the Suquía River Basin (Córdoba, Argentina). Sci Total Environ. 2014;472:389-396. https://doi.org/10.1016/j.scitotenv.2013.10.124

20. Baker DR, Kasprzyk-Hordern B. Spatial and temporal occurrence of pharmaceuticals and illicit drugs in the aqueous environment and during wastewater treatment: New developments. Sci Total Environ. 2013;454:442456. https://doi.org/10.1016/j.scitotenv.2013.03.043

21. Graham GG, Davies MJ, Day RO, Mohamudally A, Scott KF. The modern pharmacology of paracetamol: therapeutic actions, mechanism of action, metabolism, toxicity and recent pharmacological findings. Inflammopharmacology. 2013;21:201-232. https://doi.org/10.1007/ s10787-013-0172-x

22. Boyd GR, Reemtsma H, Grimm DA, Mitra S. Pharmaceuticals and personal care products (PPCPS) in surface and treated waters of Louisiana, USA and Ontario, Canada. Sci Total Environ. 2003;311(1-3):135-149. https://doi. org/10.1016/S0048-9697(03)00138-4

23. Heberer T. Occurrence, fate, and removal of pharmaceutical residues in the aquatic environment: A review of recent research data. Toxicol Lett. 2002;131(1-2):5-17. https://doi.org/10.1016/S0378-4274(02)00041-3

24. Nunes B, Gaio AR, Carvalho F, Guilhermino L. Behaviour and biomarkers of oxidative stress in Gambusia holbrooki after acute exposure to widely used pharmaceuticals and a detergent. Ecotoxicol Environ Saf. 2008;71(2):341354. https://doi.org/10.1016/j.ecoenv.2007.12.006

25. Brown JN, Paxéus N, Förlin L, Larsson JDG. Variations in bioconcentration of human pharmaceuticals from sewage effluents into fish blood plasma. Environ Toxicol Pharmacol. 2007;24:267-274. https://doi.org/10.1016/j. etap.2007.06.005

26. Huerta B, Jakimska A, Gros M, Rodríguez-Mozaz S, Barceló D. Analysis of multi-class pharmaceuticals in fish tissues by ultra-high-performance liquid chromatography tandem mass spectrometry. J Chromatogr A. 2013;1288:63-72. https://doi.org/10.1016/j.chroma.2013.03.001

27. Costanzo SD, Murby J, Bates J. Ecosystem response to antibiotics entering the aquatic environment. Mar Pollut Bull. 2005;51:218-223. https://doi. org/10.1016/j.marpolbul.2004.10.038

28. Steger-Hartmann T, Länge R, Schweinfurth H, Tschampel M, Rehmann I. Investigations into the environmental fate and effects of iopromide (ultravist), a widely used iodinated X-ray contrast medium. Water Res. 2002;36(1):266274. https://doi.org/10.1016/S0043-1354(01)00241-X

29. Nash JP, Kime DE, Van der Ven LT, Wester PW, Brion F, Maack G, et al. Long-term exposure to environmental concentrations of the pharmaceutical ethynylestradiol causes reproductive failure in fish. Environ Health Perspec. 2004;1725-1733. https://doi.org/10.1289/ehp.7209

30. Sjödin A, Hagmar L, Klasson-Wehler E, Bjork J, Bergman A. Influence of consumption of fatty Baltic Sea fish on plasma levels of halogenated environmental contaminants in Latvian and Swedish men. Environ Health Perspec. 2000;108:35-41. https://doi.org/10.1289/ehp.001081035

31. Stackelberg PE, Furlong ET, Meyer MT, Zaugg SD, Henderson AK, Reissman DB. Persistence of pharmaceutical compounds and other organic wastewater contaminants in a conventional drinking-water-treatment plant. Sci Total Environ. 2004;329(1):99-113. https://doi.org/10.1016/j. scitotenv.2004.03.015 
32. Makene VW, Tijani JO, Petrik LF, Pool EJ. Evaluation of cytotoxicity and inflammatory activity of wastewater collected from a textile factory before and after treatment by coagulation-flocculation methods. Environ Monit Assess. 2016;188:471. https://doi.org/10.1007/s10661-016-5441-x

33. Lapointe BE, Herren LW, Debortoli DD, Vogel MA. Evidence of sewage-driven eutrophication and harmful algal blooms in Florida's Indian River Lagoon. Harmful Algae. 2015;43:82-102. https://doi.org/10.1016/j.hal.2015.01.004

34. Thornber CS, Di Milla P, Nixon SW, McKinney RA. Natural and anthropogenic nitrogen uptake by bloom-forming macroalgae. Marine Poll Bull. 2008;56(2):261-269. https://doi.org/10.1016/j.marpolbul.2007.10.031

35. Paerl HW, Hall NS, Calandrino ES. Controlling harmful cyanobacterial blooms in a world experiencing anthropogenic and climatic-induced change. Sci Total Environ. 2011;409(10):1739-1745. https://doi.org/10.1016/j. scitotenv.2011.02.001

36. Qi F, Xu B, Chen Z, Ma J, Sun D, Zhang L. Efficiency and products investigations on the ozonation of 2-methylisoborneol in drinking water. Water Environ Res. 2009;81(12):2411-2419. https://doi.org/10.2175/106143009X425933

37. Pisarenko AN, Stanford BD, Yan D, Gerrity D, Snyder SA. Effects of ozone and ozone/peroxide on trace organic contaminants and NDMA in drinking water and water reuse applications. Water Res. 2012;46(2):316-326. https://doi. org/10.1016/j.watres.2011.10.021

38. Li X, Huang $Y$, Wang D. Efficiency and mechanism of degradation of 2-methylisoborneol (2-MIB) by $03 / \mathrm{H} 202$ in water. In: Proceedings of the 4th International Conference on Bioinformatics and Biomedical Engineering (iCBBE); 2010 June 18-20; Chengdu, China. IEEE; 2010. p. 1-4. http:// dx.doi.org/10.1109/ICBBE.2010.5516282

39. Zoschke K, Dietrich N, Bornick H, Worch E. UV-based advanced oxidation processes for the treatment of odour compounds: Efficiency and by-product formation. Water Res. 2012;46(16):5365-5373. https://doi.org/10.1016/j. watres.2012.07.012

40. Rosa JM, Fileti AMF, Tambourgi EB, Santana JCC. Dyeing of cotton with reactive dyestuffs: The continuous reuse of textile wastewater effluent treated by ultraviolet/hydrogen peroxide homogeneous photocatalysis. J Cleaner Prod. 2015;90:60-65. https://doi.org/10.1016/j.jclepro.2014.11.043

41. Wang D, Bolton JR, Andrews SA, Hofmann R. UV/chlorine control of drinking water taste and odour at pilot and full-scale. Chemosphere. 2015;136:239244. https://doi.org/10.1016/j.chemosphere.2015.05.049

42. Sarathy SR, Mohseni M. An overview of UV-based advanced oxidation processes for drinking water treatment. IUVA News. 2016;7(1):1-12.

43. Nam SW, Yoon Y, Choi DJ, Zoh KD. Degradation characteristics of metoprolol during UV/chlorination reaction and a factorial design optimization. J Hazard Mater. 2015;285:453-463. https://doi.org/10.1016/j.jhazmat.2014.11.052
44. Fotiou T, Triantis TM, Kaloudis T, O'Shea KE, Dionysiou DD, Hiskia A. Assessment of the roles of reactive oxygen species in the UV and visible light photocatalytic degradation of cyanotoxins and water taste and odor compounds using C-TiO . Water Res. 2016;90:52-61. https://doi. org/10.1016/j.watres.2015.12.006

45. Jiang DL, Ni GW, Zhang YM, Su YP. Algal control by low-frequency, low-power ultrasonic in eutrophic water bodies. Adv Mater Res. 2012;433-440:811816.

46. Kohno M, Ozawa T, Niwano Y. Free radical formation from sonolysis of water in the presence of different gases. J Clin Biochem Nutr. 2011;49(2):96-101. https://doi.org/10.3164/jcbn.10-130

47. Badmus KO, Tijani J, Eze CP, Fatoba O, Petrik LF. Quantification of radicals generated in a sonicator. Anal Bioanal Chem Res. 2016;3(1):139-147.

48. Pestana CJ, Robertson PKJ, Edwards C, Wilhelm W, McKenzie C, Lawton LA. A continuous flow packed bed photocatalytic reactor for the destruction of 2-methylisoborneol and geosmin utilising pelletised $\mathrm{TiO}_{2}$. Chem Eng $\mathrm{J}$. 2014;235:293-298. https://doi.org/10.1016/j.cej.2013.09.041

49. Nyamukamba P, Tichagwa L, Mamphweli S, Petrik L. Silver/carbon codoped titanium dioxide photocatalyst for improved dye degradation under visible light. Int J Photoenergy. 2017; Art. \#3079276, 9 pages. https://doi. org/10.1155/2017/3079276

50. Park J, Nama H, Choi J, Ha J, Lee S. Oxidation of geosmin and 2-methylisoborneol by the photo-Fenton process: Kinetics, degradation intermediates, and the removal of microcystin-LR and trihalomethane from Nak-Dong River water, South Korea. Chem Eng J. 2017;313:345-354. https://doi.org/10.1016/j.cej.2016.12.086

51. Mouele MES, Jimoh 0, Fatoba 00, Petrik LF. Degradation of organic pollutants and microorganisms from wastewater using different dielectric barrier discharge configurations - A critical review. Environ Science Pollut R 2015;22(23):18345-18362. https://doi.org/10.1007/s11356-015-5386-6

52. Tijani JO, Mouele MES, Tottito TC, Fatoba 00, Petrik LF. Degradation of 2-nitrophenol by dielectric barrier discharge system: the influence of carbon doped $\mathrm{TiO}_{2}$ photocatalyst supported on stainless steel mesh. J Plasma Chem Plasma Process. 2017;37(5):1343-1373. https://doi.org/10.1007/s11090017-9824-8

53. Li M, Xue Q, Zhang Z, Feng C, Chen N, Lei X, et al. Removal of geosmin (trans-1, 10-dimethyl-trans-9-decalol) from aqueous solution using an indirect electrochemical method. Electrochim Acta. 2010;55(23):6979 6982. https://doi.org/10.1016/j.electacta.2010.06.060

54. Robins S. The 2011 toilet wars in South Africa: Justice and transition between the exceptional and the everyday after apartheid. Dev Change. 2014;45(3):479-501. 